\title{
Composição aminoacídica e digestibilidade ileal de aminoácidos de alimentos energéticos determinados com suínos submetidos à anastomose ileo-retal
}

\author{
[Amino acids composition and ileal digestibility of amino acids in energetics feedstuffs measured in pigs \\ with ileo-rectal anastomosis] \\ D.O. Fontes ${ }^{1}$, J.L. Donzele ${ }^{2}$, A.G. Mascarenhas ${ }^{3}$, L.R. Apolônio ${ }^{3}$, F.C.O. Silva ${ }^{4}$ \\ F.A.P.V. Fontes ${ }^{5}$, G.S.S. Corrêa ${ }^{5}$ \\ ${ }^{1}$ Escola de Veterinária - UFMG \\ Caixa Postal 567 \\ Belo Horizonte - MG \\ ${ }^{2}$ Departamento de Zootecnia - UFV - Viçosa, MG \\ ${ }^{3}$ Aluno de pós-graduação - UFV - Viçosa, MG \\ ${ }^{4}$ EPAMIG - Viçosa, MG \\ ${ }^{5}$ Aluna de pós-graduação - EV - UFMG - Belo Horizonte, MG
}

\begin{abstract}
RESUMO
Com o objetivo de determinar os coeficientes de digestibilidade ileal aparente (CDA) dos aminoácidos de alimentos energéticos foi realizado um ensaio de metabolismo com suínos machos castrados submetidos à anastomose íleo-retal com isolamento do intestino grosso, utilizando-se o método da coleta total de excretas e três repetições por alimento avaliado. Os animais cujo peso médio inicial foi de $35,1 \mathrm{~kg}$ foram alojados em gaiolas de metabolismo sendo um animal por unidade experimental. Os alimentos avaliados (milho comum, milho de alta proteína, milheto, sorgo e farelo de trigo) constituíram a única fonte protéica das dietas, isoprotéicas em $8 \%$ de PB. As dietas foram fornecidas duas vezes ao dia e a sua quantidade calculada com base no peso metabólico dos animais. A glicina, treonina e prolina apresentaram os menores CDA (respectivamente 49,37; 59,36 e 59,62\%), enquanto arginina e ácido glutâmico, os maiores valores, (respectivamente 89,67 e $85,09 \%$ para o CDA). Os dados obtidos podem ser utilizados como referência para a formulação de dietas para suínos em crescimento com base em aminoácidos digestíveis.
\end{abstract}

Palavras-chave: aminoácidos, anastomose íleo-retal, digestibilidade ileal, suínos

\begin{abstract}
A metabolism assay that utilized pigs ileo-rectal anastomosis with complete isolation of large intestine was conducted to determine aparent (ADC) ileal amino acids digestibility coefficients of energetic feedstuffs for swine. The method employed was the total feces collection with three repetitions for evaluated feedstuff. The pigs, averaging $35,5 \mathrm{~kg}$ initial live weight, were allotted in metabolism cages. The metabolism cage was considerate one experimental unit. The valued feedstuffs (corn, QPM corn, millet, sorghum and wheat bran) was single protein source of diets, every one with $8 \%$ of crude protein. The diets was provide in twice time and the quantity calculated of accord with the metabolic weight. In the feedstuffs evaluated glycine, threonine and proline exhibited the smaller values of ADC (respectively, 49,37; 59,36 and 59,62\%), whereas arginine and glutamic acid presented the greater values of ADC (respectively, 89,67 and 85,09\%).
\end{abstract}

Keywords: Amino acids, digestibility, ileo-retal anastomosis, swine

Recebido em 10 de outubro de 2006

Aceito em 17 de janeiro de 2007

E-mail: dalton.vet@ufmg.br

Apoio: FAPEMIG 


\section{INTRODUÇÃO}

Um grande desafio para os nutricionistas é formular dietas utilizando alimentos, que forneçam, a um mínimo custo, a quantidade de aminoácidos essenciais necessários para garantir o máximo desempenho dos animais. Para isso, é necessário conhecer a quantidade de aminoácidos presentes no alimento e a quantidade biologicamente disponível (Laplace, 1986; Tanksley e Knabe, 1993). Entretanto, valores relativos a digestibilidade ileal dos aminoácidos devem ser preferidos em relação aos valores de digestibilidade fecal, em função das possíveis interferências da flora bacteriana no metabolismo de aminoácidos no intestino grosso (Fan e Sauer, 1995).

A maioria das proteínas e aminoácidos que entram no intestino grosso são de pouco ou nenhum valor nutricional para o suíno (Fuller et al., 1994), sendo excretadas ou incorporadas nas proteínas microbianas, a qual representa a maior fração do nitrogênio fecal (Laplace et al., 1994). Desse modo, a digestibilidade ileal é teoricamente a melhor estimativa da disponibilidade dos aminoácidos em relação à digestibilidade fecal.

Quando se formula dietas de suínos com alimentos alternativos utilizando o conceito da digestibilidade dos aminoácidos, aumenta-se a precisão da formulação (Bellaver, 1996). Nesse sentido, conhecer os valores de digestibilidade ileal dos aminoácidos, de diferentes alimentos, se faz necessário.

Esse trabalho foi realizado com o objetivo de determinar a composição em aminoácidos e os valores dos coeficientes de digestibilidades ileal aparente dos aminoácidos do milho, milho de alta proteína, milheto, sorgo de baixo tanino e farelo de trigo, utilizando suínos em crescimento submetidos à anastomose íleo-retal com isolamento completo do intestino grosso.

\section{MATERIAL E MÉTODOS}

O experimento foi conduzido nas instalações do setor de suinocultura do Departamento de Zootecnia da Universidade Federal de Viçosa.

Foram utilizados três suínos machos castrados mestiços, submetidos à anastomose íleo-retal com isolamento do intestino grosso e com o peso inicial médio de $35,1 \mathrm{~kg}$. O procedimento cirúrgico foi realizado no centro cirúrgico de grandes animais, do Departamento de Veterinária, da Universidade Federal de Viçosa, segundo técnica descrita por Lopes et al. (1998).

Os animais foram alojados em gaiolas de metabolismo semelhantes às descritas por Pekas (1968), localizadas em sala de alvenaria, com piso de concreto, teto de madeira rebaixado e janelas de vidro tipo basculante. $\mathrm{O}$ ambiente foi climatizado mantendo-se a temperatura constante entre 20 e $22^{\circ} \mathrm{C}$.

O período experimental para avaliação de cada alimento foi de 12 dias, sendo sete dias para adaptação às gaiolas e às rações experimentais e para regularização do consumo e cinco dias de coleta de digesta. Para cada alimento avaliado foram utilizadas três repetições, sendo um animal por unidade experimental.

Os alimentos avaliados foram milho comum, milho de alta proteína, milheto, sorgo (baixo tanino) e farelo de trigo, que continham $8,6 \%$, $11,9 \%, 13,0 \%, 8,6 \%$ e $15,7 \%$ de proteína bruta (PB) respectivamente. Para cada alimento foi formulada uma ração experimental (Tab. 1), onde os alimentos avaliados constituíram a única fonte de proteína dessas dietas, sendo isoprotéicas em $8 \%$ de proteína bruta.

As dietas fornecidas duas vezes ao dia, às 8 e 16 horas, em quantidades calculadas com base no tamanho metabólico $\left(\mathrm{kg}^{0,75}\right)$, foram umedecidas para evitar perdas e facilitar a ingestão. Os animais receberam água a vontade após o consumo de toda a ração.

A coleta total de digesta foi realizada diariamente, em duas vezes, uma pela manhã e outra à tarde. Após a pesagem, a digesta foi homogeneizada para a retirada de uma amostra de $20 \%$ do total, acondicionada individualmente em saco plástico devidamente identificado, e armazenado em à $10^{\circ} \mathrm{C}$, até a realização das análises laboratoriais.

Ao final do período experimental as amostra de cada animal foram descongeladas, homogeneizadas e retirada uma amostra de aproximadamente $500 \mathrm{~g}$ por animal para secagem em estufa de ventilação forçada a $65^{\circ} \mathrm{C}$, por no mínimo 72 horas. As amostras moídas em 
moinho tipo bola foram armazenadas em recipientes de vidro, e mantidas em geladeira até a realização das análises laboratoriais.

As análises de aminoácidos nos alimentos, nas dietas e nas digestas foram realizadas no
Laboratório da Guabi - Mogiana Alimentos S/A Campinas, SP, utilizando-se o analisador de aminoácidos HITACHI modelo 8500 A. O aminoácido triptofano não foi determinado.

Tabela 1. Composição centesimal das dietas experimentais

\begin{tabular}{|c|c|c|c|c|c|}
\hline \multirow[b]{2}{*}{ Ingrediente (\%) } & \multicolumn{5}{|c|}{ Dieta experimental } \\
\hline & $\begin{array}{l}\text { Milho } \\
\text { comum }\end{array}$ & $\begin{array}{l}\text { Milho alta } \\
\text { proteína }\end{array}$ & Sorgo & Milheto & Far. Trigo \\
\hline Milho & 92,80 & 67,20 & - & - & - \\
\hline Sorgo & - & - & 93,10 & - & - \\
\hline Milheto & - & - & - & 61,60 & - \\
\hline Farelo trigo & - & - & - & - & 50,90 \\
\hline Fosfato bicálcico & 1,50 & 1,65 & 1,54 & 1,61 & 1,10 \\
\hline Calcário & 1,24 & 1,17 & 1,20 & 1,20 & 1,42 \\
\hline Sal & 0,4 & 0,4 & 0,4 & 0,4 & 0,4 \\
\hline Premix Mineral $^{1}$ & 0,05 & 0,05 & 0,05 & 0,05 & 0,05 \\
\hline Premix Vitamínico $^{2}$ & 0,10 & 0,10 & 0,10 & 0,10 & 0,10 \\
\hline Bacitracina de zinco & 0,05 & 0,05 & 0,05 & 0,05 & 0,05 \\
\hline BHT & 0,01 & 0,01 & 0,01 & 0,01 & 0,01 \\
\hline Óxido crômico & 0,50 & 0,50 & 0,50 & 0,50 & 0,50 \\
\hline Amido & 3,35 & 28,87 & 3,05 & 34,48 & 45,47 \\
\hline TOTAL & 100 & 100 & 100 & 100 & 100 \\
\hline \multicolumn{6}{|c|}{ Composição calculada } \\
\hline E. metabolizável (kcal/kg) & 3210 & 3277 & 3232 & 2987 & 2746 \\
\hline Proteína bruta (\%) & 8,0 & 8,0 & 8,0 & 8,0 & 8,0 \\
\hline Cálcio & 0,88 & 0,88 & 0,88 & 0,88 & 0,88 \\
\hline Fósforo disponível & 0,35 & 0,35 & 0,35 & 0,35 & 0,35 \\
\hline
\end{tabular}

As análises de matéria seca e proteína bruta dos alimentos foram realizadas segundo metodologia descrita por Silva (1990).

Os coeficientes de digestibilidade aparente dos aminoácidos foram calculados segundo Rostagno e Featherston (1977). O ensaio foi conduzido no delineamento em blocos casualizados, sendo o animal o bloco. Os dados foram analisados por meio de estatísticas descritivas.

\section{RESULTADOS E DISCUSSÃO}

Os valores de matéria seca, proteína bruta e a composição em aminoácidos essenciais e nãoessenciais do milho comum, milho de alta proteína, milheto, sorgo baixo tanino e farelo de trigo encontram-se na Tab. 2.

A composição aminoacídica dos alimentos estudados, é semelhante aos valores apresentados por Rostagno et al. (2000), com exceção da arginina em que os valores obtidos estão abaixo daqueles preconizados para o milho, milho de alta proteína, sorgo e farelo de trigo. O valor referente à composição da lisina no milheto $(0,50 \%)$ foi $44 \%$ superior ao valor de $0,35 \%$ apresentado por Rostagno et al. (2000).

Os coeficientes de digestibilidade ileal aparente (CDA) dos aminoácidos essenciais e nãoessenciais dos alimentos encontram-se na Tab. 3. 
Composição aminoacídica e digestibilidade ileal...

Tabela 2. Matéria seca, proteína bruta e composição de aminoácidos dos alimentos na matéria natural

\begin{tabular}{|c|c|c|c|c|c|}
\hline Composição (\%) & $\begin{array}{l}\text { Milho } \\
\text { comum }\end{array}$ & $\begin{array}{c}\text { Milho alta } \\
\text { proteína }\end{array}$ & Sorgo & Milheto & $\begin{array}{c}\text { Farelo de } \\
\text { trigo }\end{array}$ \\
\hline Matéria seca & 89,10 & 90,10 & 89,20 & 88,10 & 89,20 \\
\hline Proteína bruta & 8,62 & 11,90 & 8,59 & 12,98 & 15,70 \\
\hline \multicolumn{6}{|c|}{ Aminoácido essencial } \\
\hline Arginina & 0,250 & 0,394 & 0,223 & 0,497 & 0,669 \\
\hline Fenilalanina & 0,425 & 0,403 & 0,486 & 0,678 & 0,560 \\
\hline Histidina & 0,333 & 0,414 & 0,286 & 0,471 & 0,479 \\
\hline Isoleucina & 0,264 & 0,284 & 0,343 & 0,534 & 0,409 \\
\hline Leucina & 1,069 & 0,763 & 1,907 & 1,323 & 0,828 \\
\hline Lisina & 0,291 & 0,422 & 0,223 & 0,504 & 0,629 \\
\hline Metionina & 0,186 & 0,274 & 0,185 & 0,275 & 0,298 \\
\hline Treonina & 0,349 & 0,381 & 0,292 & 0,506 & 0,510 \\
\hline Valina & 0,424 & 0,485 & 0,472 & 0,756 & 0,675 \\
\hline \multicolumn{6}{|c|}{ Aminoácido não essencial } \\
\hline Alanina & 0,603 & 0,476 & 0,821 & 0,977 & 0,581 \\
\hline Ác. aspártico & 0,579 & 0,745 & 0,567 & 1,011 & 1,022 \\
\hline Ác. glutâmico & 0,535 & 1,406 & 0,876 & 2,495 & 2,612 \\
\hline Cistina & 0,206 & 0,254 & 0,166 & 0,263 & 0,325 \\
\hline Glicina & 0,300 & 0,382 & 0,259 & 0,417 & 0,651 \\
\hline Prolina & 0,817 & 0,818 & 0,841 & 0,832 & 0,902 \\
\hline Serina & 0,423 & 0,405 & 0,388 & 0,590 & 0,587 \\
\hline Tirosina & 0,205 & 0,234 & 0,231 & 0,282 & 0,331 \\
\hline
\end{tabular}

${ }^{1}$ Análise realizada no laboratório da Guabi - Mogiana Alimentos

Observou-se tendência dos alimentos farelo de trigo e milho comum apresentarem os maiores coeficientes médios de digestibilidade aparente dos aminoácidos essenciais ao quais apresentaram valores de 80,60 e $80,58 \%$, respectivamente.

Lisina e treonina foram os aminoácidos essenciais que apresentaram os coeficientes de digestibilidade aparente em 68,87 e 67,93\%, respectivamente, para o milho comum, $65,78 \mathrm{e}$ $56,93 \%$ para o milheto e 66,08 e $53,37 \%$ para o sorgo. No milho de alta proteína e no farelo de trigo, os aminoácidos que apresentaram numericamente, os menores coeficientes de digestibilidade foram a isoleucina e a treonina. Essa tendência de apresentarem os menores valores de digestibilidade da lisina e da treonina têm importância prática uma vez que, juntamente com o triptofano, são os primeiros aminoácidos limitantes para suínos alimentados com rações a base de grãos (Lin et al., 1987).

A glicina foi o aminoácido não-essencial que apresentou numericamente os menores coeficientes de digestibilidade ileal aparente, entre os alimentos, excetuando-se o farelo de trigo, em que a alanina apresentou o menor coeficiente de digestibilidade. $O$ menor coeficiente de digestibilidade da glicina pode estar relacionado ao fato de que este aminoácido estar presente em quantidade relativamente elevada na proteína endógena, representando cerca de $13 \%$ do nível de aminoácidos endógenos na digesta ileal (Sauer et al., 1977). 
Tabela 3. Coeficientes de digestibilidade ileal aparente e desvios padrão dos aminoácidos de alguns alimentos energéticos obtidos com suínos em crescimento

\begin{tabular}{|c|c|c|c|c|c|c|}
\hline $\begin{array}{c}\text { Aminoácido } \\
(\%)\end{array}$ & $\begin{array}{l}\text { Milho } \\
\text { comum }\end{array}$ & $\begin{array}{l}\text { Milho alta } \\
\text { proteína }\end{array}$ & Milheto & Sorgo & Farelo de trigo & Média \\
\hline \multicolumn{7}{|l|}{ Essencial } \\
\hline Arginina & $89,680 \pm 1,54$ & $92,173 \pm 0,05$ & $90,773 \pm 0,40$ & $77,943 \pm 3,16$ & $97,770 \pm 2,23$ & 89,668 \\
\hline Histidina & $87,337 \pm 2,25$ & $85,327 \pm 3,84$ & $84,247 \pm 4,40$ & $72,750 \pm 2,59$ & $82,680 \pm 2,03$ & 82,468 \\
\hline Isoleucina & $73,553 \pm 1,54$ & $57,940 \pm 4,71$ & $70,530 \pm 5,55$ & $72,207 \pm 3,10$ & $73,820 \pm 2,73$ & 69,610 \\
\hline Leucina & $86,403 \pm 0,82$ & $71,160 \pm 2,67$ & $77,723 \pm 3,99$ & $82,800 \pm 2,25$ & $77,480 \pm 2,16$ & 79,113 \\
\hline Lisina & $68,867 \pm 1,23$ & $70,153 \pm 3,68$ & $65,777 \pm 9,30$ & $59,683 \pm 3,34$ & $79,720 \pm 2,89$ & 68,880 \\
\hline Metionina & $90,937 \pm 4,61$ & $91,003+4,52$ & $75,590 \pm 10,66$ & $66,077 \pm 12,43$ & $88,090 \pm 6,00$ & 82,339 \\
\hline Fenilalanina & $83,243 \pm 1,03$ & $72,863 \pm 1,86$ & $78,530 \pm 3,45$ & $80,617 \pm 2,53$ & $80,630 \pm 1,79$ & 79,177 \\
\hline Treonina & $67,927 \pm 1,32$ & $50,643+5,83$ & $56,933+9,24$ & $53,373+4,58$ & $67,927 \pm 3,83$ & 59,361 \\
\hline Valina & $77,250 \pm 1,50$ & $66,190 \pm 4,28$ & $73,057 \pm 5,45$ & $73,637 \pm 2,67$ & $77,273 \pm 2,39$ & 73,481 \\
\hline Média (AAE) & 80,577 & 73,050 & 74,795 & 71,010 & 80,599 & \\
\hline \multicolumn{7}{|l|}{ Não essencial } \\
\hline Alanina & $77,010+1,85$ & $44,880 \pm 7,77$ & $69,143 \pm 6,15$ & $74,103+3,19$ & $56,933+2,10$ & 64,413 \\
\hline Ác. aspártico & $73,350 \pm 0,67$ & $64,907 \pm 4,99$ & $66,190 \pm 9,12$ & $67,363+2,80$ & $74,930 \pm 1,86$ & 69,348 \\
\hline Ác. glutâmico & $86,817 \pm 0,69$ & $79,097 \pm 3,22$ & $83,563 \pm 4,29$ & $85,990 \pm 1,71$ & $89,980 \pm 0,73$ & 85,089 \\
\hline Cistina & $84,850 \pm 1,66$ & $80,027 \pm 2,99$ & $80,087 \pm 3,89$ & $81,583 \pm 4,95$ & $81,000 \pm 12,01$ & 81,509 \\
\hline Glicina & $57,040 \pm 3,10$ & $44,303 \pm 4,64$ & $46,687 \pm 9,77$ & $32,513 \pm 10,55$ & $66,313 \pm 3,66$ & 49,371 \\
\hline Prolina & $67,840 \pm 11,99$ & $62,737 \pm 8,38$ & $62,567 \pm 6,51$ & $46,133 \pm 19,89$ & $58,813 \pm 17,13$ & 59,618 \\
\hline Serina & $78,997 \pm 0,70$ & $65,240 \pm 4,04$ & $69,933 \pm 6,93$ & $69,553 \pm 3,08$ & $76,790 \pm 2,95$ & 72,103 \\
\hline Tirosina & $77,617 \pm 1,38$ & $71,280 \pm 2,42$ & $75,740 \pm 3,16$ & $77,543 \pm 2,83$ & $76,597 \pm 2,57$ & 75,755 \\
\hline Média (AANE) & 75,440 & 64,059 & 69,239 & 66,848 & 72,670 & \\
\hline
\end{tabular}

A lisina apresentou numericamente diferentes valores de digestibilidade para os alimentos avaliados, sendo que com exceção dos baixos coeficientes de digestibilidade aparente do sorgo $(59,68 \%)$ e do milheto $(65,78 \%)$ e dos altos valores observados no farelo de trigo $(79,72 \%)$, os valores obtidos para milho $(68,87 \%)$, milho de alta proteína $(70,15 \%)$, estão consistentes com aqueles apresentados em Ileal... (2000), que correspondem a 67 e $68 \%$, respectivamente. Do mesmo modo que os resultados obtidos neste estudo, os coeficientes de digestibilidade aparente da lisina no farelo de trigo obtidos por Thiré (1986) e por Parsons (1996) também foram superiores.

No milho comum, os coeficientes de digestibilidade aparente obtidos para a leucina $(86,40 \%)$, metionina $(90,94 \%)$, fenilalanina $(83,24 \%)$, treonina $(67,93 \%)$ e valina $(77,25 \%)$ foram semelhantes aos referendados por NRC (1998), que correspondem a 88,$0 ; 86,0 ; 83,0$; 69,0 ; e $79,0 \%$, respectivamente. Os valores obtidos para a arginina $(89,68 \%)$, histidina $(87,34 \%)$ e fenilalanina $(83,24 \%)$ foram similares aos apresentados por Lin et al. (1987), que corresponderam a 88,$6 ; 85,1$; e $87,7 \%$, respectivamente, enquanto os coeficientes obtidos para os demais aminoácidos essenciais foram inferiores aos apresentados por aqueles autores.

Os coeficientes de digestibilidade aparente dos aminoácidos essenciais do milho de alta proteína variaram de $50,64 \%$ da treonina a $92,17 \%$ da arginina. Oliveira (1997) encontraram uma variação de $57,5 \%$ da isoleucina a $93,3 \%$ da arginina. Entretanto, Sullivan et al. (1989) observaram para os aminoácidos essenciais do milho de alta proteína variação de $72, \%$ para isoleucina e $88 \%$ para arginina.

No farelo de trigo, o coeficiente médio de digestibilidade aparente dos aminoácidos essenciais foi de $80,60 \%$, sendo a treonina o aminoácido que apresentou o menor valor $(67,93 \%)$ e a arginina o maior $(97,77 \%)$. Os coeficientes de digestibilidade obtidos para a isoleucina $(73,82 \%)$, metionina $(88,09 \%)$, fenilalanina $(80,63 \%)$, treonina $(67,93 \%)$ e 
valina $(77,27 \%)$ foram superiores aos valores apresentados por Thiré (1986), que corresponderam a 63,$9 ; 72,1 ; 71,5 ; 62,3 ; 70 \%$, respectivamente. $\mathrm{O}$ coeficiente de digestibilidade aparente para a lisina $(79,72 \%)$ foi similar ao valor encontrado por Parsons (1996), que correspondeu a $80 \%$ e inferior ao valor de $85,9 \%$ obtido por Thiré (1986).

No sorgo, os valores de digestibilidade aparente foi $82,80 \%$ para leucina, $59,68 \%$ para lisina e $53,37 \%$ para treonina. Os menores valores de digestibilidade destes dois aminoácidos, verificados neste trabalho, corrobora os resultados de Lin et al. (1987), que também encontraram menores coeficientes de digestibilidade aparente para lisina e treonina, no sorgo. Dentre os alimentos avaliados, os menores coeficientes de digestibilidade aparente para os aminoácidos essenciais arginina (77,94\%), histidina $(72,75 \%)$, lisina $(59,68 \%)$, metionina $(66,08 \%)$ e treonina $(53,37 \%)$ foram obtidos para o sorgo. Os coeficientes de digestibilidade obtidos para arginina $(77,94 \%)$, histidina $(72,75 \%)$ e fenilalanina $(80,62 \%)$ foram similares aos referendados em NRC (Nutrient..., 1998), que correspondem a 78; 73; e $81 \%$, respectivamente.

Quanto ao milheto, o coeficiente de digestibilidade médio dos aminoácidos essenciais foi de $74,80 \%$, com o maior coeficiente de digestibilidade sendo obtido para arginina $(90,77 \%)$, e o menor para a treonina $(56,93 \%)$. O baixo coeficiente de digestibilidade da treonina pode ser explicado por sua alta concentração na mucina da mucosa intestinal (Fuller, 1994) e pela sua baixa velocidade de absorção (Fan et al., 1995).

Os coeficientes de digestibilidade da isoleucina $(70,53 \%)$, leucina $(77,72 \%)$, fenilalanina $(78,53 \%)$, treonina $(56,93 \%)$, valina $(73,06 \%)$ e lisina $(65,78 \%)$ no milheto, valores estes menores do que os apresentados no NRC (1998), que correspondem a $83 ; 87 ; 85 ; 75 ; 81$ e $74 \%$, respectivamente.

É importante se considerar a variação na digestibilidade dos aminoácidos dentro de cada cereal. Sauer e Ozimek (1986), citam para a lisina variações de 65 a $79 \%$ na cevada, 62 a $81 \%$ no trigo e 71 a $82 \%$ no milho. Essa variação pode ser ainda maior se considerarmos os valores encontrados para lisina no milho por Thiré (1986), Oliveira (1997) e por Parsons (1996) que foram de 49,7; 65 e $80 \%$ respectivamente.

Uma grande parte dessa variação pode está relacionada com o conteúdo relativamente baixo de aminoácidos nos grãos de cereais (Sauer e Ozimek, 1886). Pequenas mudanças nos níveis de aminoácidos endógenos podem explicar grandes variações nos valores de digestibilidade aparente dos aminoácidos, uma vez que é expressa como porcentagens, principalmente para os que ocorrem em pequenos níveis nos grãos como lisina e triptofano e para aqueles que se encontram em concentrações relativamente elevadas nas secreções endógenas como a treonina, glicina e prolina.

Além disso, as diferenças na composição e digestibilidade de aminoácidos podem ser devido a vários outros fatores como variedade do grão, aplicação de fertilizantes e condições ambientais. Esses fatores alteram as quantidades totais $\mathrm{e}$ relativas das principais proteínas da semente (albuminas, globulinas, prolaminas e gluteninas), resultando, em alterações na digestibilidade dos aminoácidos (Sauer e Ozimek, 1986).

\section{CONCLUSÕES}

Os dados obtidos podem ser utilizados como referência da composição aminoacídica do milho comum, milho de alta proteína, sorgo baixo tanino, milheto e farelo de trigo. A digestibilidade dos aminoácidos desses alimentos é referência para a formulação de dietas para suínos em crescimento com base em aminoácidos digestíveis.

\section{REFERÊNCIAS BIBLIOGRÁFICAS}

BELLAVER, C. Predição da digestibilidade de aminoácidos In Vivo com suínos. In: SIMPÓSIO LATINO-AMERICANO DE NUTRIÇÃO ANIMAL E SEMINÁRIO SOBRE TECNOLOGIA DA PRODUÇÃO DE RAÇÕES, 1996, Campinas, SP. Anais...Campinas, CBNA, 1996.

FAN, M.Z.; SAUER, W.C. Determination of apparent ileal amino acid digestibility in barley and canola meal for pigs with the direct, difference, and regression methods. J. Anim. Sci., v.73, p.23642374, 1995. 
FAN, M.Z.; SAUER, W.C.; de LANGE, C.F.M Amino acid digestibility in soybean meal, extruded soybean and full-fat canola for early-weaned pigs. Anim. Feed Sci. Techn., v.52, p.189-203. 1995.

FULLER, M.F. Amino acids requirements for mantenance, body protein accretion and reproduction in pigs. In: D'Mello, J.P.F. Amino acids in farm animal nutrition. The Scottish Agrigultural College, Edinburgh, p. 155-184, 1994.

FULLER, M.F.; DARCY, B.V.; LAPLACE, J.P. et al. The measurement of dietary amino acid digestibility in pigs, rats and chickens: a comparison of methodologies. Anim. Feed Sci. Technol., v.48, p.305-324, 1994.

ILEAL standardized digestibility of amino acids in feedstuffs pigs. Paris: AMIPIG, 2000. 43p.

LAPLACE, J.P.; SOUFFRANT, W.B.; HENNIH, $\mathrm{U}$. et al. Measurement of precaecal dietary protein and plant cell wall digestion in pigs; Comparison of four surgical procedures for íleo-rectal anastomosis. Livestock Production Sci., v.40, p.313-328, 1994.

LAPLACE, J.P. Aminno acids availability in pig feeding. In: WORLD CONGRESS OF ANIMAL FEEDING, Madrid, 1986, IV. Anais... Madrid, Spain, p.109-129, 1986.

LIN, F.S.; KNABE, D.A.; TANKSLEY Jr., T.D. Apparent digestibility of amino acids, gross energy and starch in corn, sorghum, wheat, barley, oat groats and wheat middling for growing pigs. $J$. Anim. Sci., v.64, p.1655-1663, 1987.

LOPES, M.A.F.; FONTES, D.O.; SOUZA, A.V.C.; ANTUNES, F.; POMPERMAYER, L.G.; SILVA, J.C.P. Anastomose íleo-retal em suínos com colostomia (técnica de LAPLACE modificada). In: REUNIÃO ANUAL DA SOCIEDADE BRASILEIRA DE ZOOTECNIA, 35, 1998, Botucatu. Anais... Botucatu: SBZ, 1998, v.4, p.327329.

NUTRIENT requirements of swine. 10.ed., Washington, National Academic of Sciences. 189 p.

OLIVEIRA, S.G. Digestibilidade ileal dos aminoácidos essenciais de milhos de alto valor protéico para suínos. 1997. 58f. Tese (Doutorado) Escola de Veterinária, Universidade Federal de Minas Gerais, Belo Horizonte, MG.

PARSONS, C.M. Digestible amino acids for poultry and swine. Anim. Feed Sci. Technol., v.59, p.147-153, 1996.

PEKAS, J.C. Versatible swine laboratory apparatus for physiologic and metabolic studies. J. Anim. Sci., v.27, p.1303-1306, 1968.

ROSTAGNO, H.S., ALBINO, L.F.T.; DONZELE, J.L. Composição de alimentos e exigências nutricionais (Tabelas Brasileiras para Aves $e$ Suínos). Viçosa: UFV, 2000. 141p.

ROSTAGNO, H.S., FEATHERSTON, W.R. Estudos de métodos para determinação da disponibilidade de aminoácidos. R. Bras. Zootec., v.6, p.64-75, 1977.

SAUER, W.C.; STOTHERS, S.C.; PARKER, R.J. Apparent and true availabilities of amino acids in wheat and milling by-products for growing pigs. Can. J. Anim. Sci., v.57, p.775-784, 1977.

SAUER, W.C.; OZIMEK, L. Digestibility of amino acids in swine: Results and their practical applications. A review. Livest. Product. Sci., v.15, p.367-388, 1986.

SILVA, D.J. Análise de alimentos (métodos químicos e biológicos). Viçosa: UFV. 1990. 165p.

SULLIVAN, J.S.; KNABE, D.A.; BOCKHOLT, A.J. et al. Nutritional value of quality protein maize and food corn for starter and growth pigs. J. Anim. Sci., v.67, p.1285-1289, 1989.

TANKSLEY Jr., T.D.; KNABE, D.A. Ileal digestibility of amino acids in pigs feeds and their use in formulating diets. In: COLE, D.J.A., HARESING, W., GARNSWORTHY, P.C. Recent Development in pig nutrition 2. Nottinghan University, 1993. 375p.

THIRÉ, M.C. Valores energéticos e digestibilidade ileal e total de aminoácidos em alimentos brasileiros para suínos. Viçosa, MG: UFV, 1986. 65f. Dissertação (Mestrado) - Universidade Federal de Viçosa, Viçosa, MG. 